\title{
A Unique Elastase in Human Blood Platelets
}

\author{
H. L. James, Y. T. Wachtfogel, P. L. James, M. Zimmerman, R. W. Colman, and A. B. Cohen \\ Departments of Medicine and Physiology and the Thrombosis Research Center, Temple University School of Medicine, Philadelphia, \\ Pennsylvania 19140; and Department of Immunology, Merck Sharp \& Dohme Research Laboratories, Rahway, New Jersey 07065
}

\begin{abstract}
Previous investigations suggested that elastolytic activity found in platelets could be due to contamination by neutrophil elastase. In the present study, the lysate of blood platelets free of detectable neutrophils was examined for elastase-like activity using tertiary-butyloxycarbonyl (tBOC)-ala-ala-pro-ala-aminomethyl coumarin (I), tBOC-ala-ala-pro-val-aminomethyl coumarin (II), and succinyl-tri-ala-p-nitroanilide (SAPNA), and for elastolytic activity using ${ }^{3} \mathrm{H}$-labeled dog and human lung elastins. The platelet lysate degraded I at a higher rate than II, while the reverse was true of neutrophil elastase. The rate of degradation of I, II, and SAPNA by the lysate increased with reaction time up to $20 \mathrm{~min}$. The rate of I, II, and SAPNA degradation by the lysate was decreased by the presence of $0.5 \mathrm{M} \mathrm{NaCl}$, whereas $\mathrm{NaCl}$ greatly potentiated their degradation by neutrophil elastase. Plasma $\alpha_{2}$-macroglobulin inhibited elastolysis by the platelet lysate, whereas plasma $\alpha_{1}$-antitrypsin did not. The lysate activity was inhibited by diisopropyl fluorophosphate, phenylmethylsulfonyl fluoride, elastatinal, Trasylol, and furoyl-saccharin. The optimum pH for platelet lysate activity was 8.5-9.0, as in other studies using elastin as substrate. The pH 4.5 eluate obtained after incubation of the lysate with dog lung elastin at neutral $\mathrm{pH}$ exhibited the same catalytic properties as the activity in the lysate. The different substrate and inhibitor specificities and the failure of IgG specific for neutrophil elastase to remove elastaselike and elastolytic activities from the lysate indicate that a unique elastase occurs in platelets.
\end{abstract}

\section{Introduction}

Robert et al. (1) demonstrated that platelets liberate elastolytic activity. They used azo-elastin, orcein elastin, and ${ }^{125} \mathrm{I} /{ }^{131} \mathrm{I}$-labeled elastin from bovine ligamentum nuchae as substrates. The activity was found in both particulate and soluble fractions of the platelets $(2,3)$. Addition of trypsin to either the initial Triton extract or to the $40 \%$ ammonium sulfate precipitate increased the capacity of the extract to degrade ${ }^{125}$ I-elastin, suggesting that a proelastase occurs in platelets. Platelet proelastase was shown to have a molecular weight of $\sim 30,000$ and was converted to elastase with a molecular weight of 26,000 (4). The elastolytic activity was enriched by affinity chromatography on elastin. Legrand et al. (5) found that, unlike neutrophil elastase $(6,7)$,

Dr. H. L. James, Mr. P. L. James, and Dr. Cohen are currently with the University of Texas Health Center, Tyler, TX 75710.

Address reprint requests to Dr. H. L. James. 1985.

Received for publication 20 April 1984 and in revised form 20 Augus

J. Clin. Invest.

(c) The American Society for Clinical Investigation, Inc.

$0021-9738 / 85 / 12 / 2330 / 08 \quad \$ 1.00$

Volume 76, December 1985, 2330-2337 platelet elastase had no bound carbohydrate, and had an aminoterminal valine.

Although the foregoing evidence indicates that a unique elastase occurs in platelets, this claim was disputed by Ehrlich and Gordon (8), who found no elastolytic activity in platelet preparations contaminated with less than one neutrophil per $10^{8}$ platelets. Subsequently, Starkey et al. (9) attempted to demonstrate elastolytic activity with ${ }^{3} \mathrm{H}$-labeled elastin, elastin-agarose plates, and a synthetic substrate, tertiary-butyloxycarbonyl (tBOC)-L-alanine-2-naphthyl ester. No significant elastase activity was observed.

The present studies employed extracts of platelets which were free of contaminating neutrophils to determine whether there is an elastase in platelets that is different from neutrophil elastase. Substrate specificities, inhibitor profiles, and ability to bind to antibody against neutrophil elastase were utilized to establish the uniqueness of the platelet enzyme.

\section{Methods}

Materials. Bovine serum albumin (A-9647), prostaglandin $\mathrm{E}_{1}\left(\mathrm{PGE}_{1}\right)^{1}$, Sepharose 4B, Sephadex G-200, cyanogen bromide, soybean trypsin inhibitor (SBTI), and the trypsin substrates, $N$-benzoyl-arginine ethyl ester $\mathrm{HCl}$ (BAEe) and $N$ - $\alpha$-benzoyl-D,L-arginine- $p$-nitroanilide (BAPNA), were obtained from Sigma Chemical Co., St. Louis, MO. The Whatman brand of DEAE-cellulose, DE-52, was purchased from Whatman Chemical Separations, Inc., Clifton, NJ. The substrate for elastase-like activity, succinyl-tri-alanine-p-nitroanilide (SAPNA), was obtained from the Protein Research Foundation, Osaka, Japan. The fluorescence-labeled tetrapeptide substrates for elastase-like activity, tBOC-ala-ala-pro-alaaminomethyl coumarin (compound I) and tBOC-ala-ala-pro-val-aminomethyl coumarin (compound II), as well as the elastase inhibitor, furoyl-saccharin, were synthesized in one of our laboratories (Dr. Zimmerman) by previously described methods $(10,11)$. The following inhibitors of microbial origin (12) were obtained from Peninsula Laboratories, Inc., Belmont, CA: elastatinal, chymostatin, antipain, and leupeptin. The purified beef lung kallikrein inhibitor, Trasylol, was a generous gift from Prof. Haberland and Dr. Spengler of Bayer AG, Elberfeld, Federal Republic of Germany.

Highly purified plasma human alpha-1-antitrypsin was prepared by the procedure of Cohen and James (13). Human neutrophil elastase was purified to homogeneity by the procedure of Baugh and Travis (7). Antiserum specific for human neutrophil elastase was produced in goats by this laboratory. The antiserum undiluted produced a precipitin line against the antigen at $1.0 \mathrm{mg} / \mathrm{ml}$ which was equidistant between the two wells. Purified porcine pancreatic elastase was obtained by the method of Shotton (14), and crystalline bovine trypsin (code 36-555) was purchased from Miles Laboratories, Inc., Elkhart, IN. The trypsin was $51.4 \%$ active, as judged by active site titration using $p$-nitrophenyl $p$-guanidino-

1. Abbreviations used in this paper: BAEe, $N$-benzoyl-arginine ethyl ester; BAPNA, $N$ - $\alpha$-benzoyl-D,L-arginine-p-nitroanilide; compound I, tertiarybutyloxycarbonyl (tBOC)-ala-ala-pro-ala-aminomethyl coumarin; compound II, tBOC-ala-ala-pro-val-aminomethyl coumarin; DFP, diisopropyl fluorophosphate; $P E_{1}$, prostaglandin $E_{1} ; P M S F$, phenylmethylsulfonyl fluoride; PRP, platelet-rich plasma; SAPNA, succinyl-tri-alanine-p-nitroanilide; SBTI, soybean trypsin inhibitor. 
benzoate- $\mathrm{HCl}$ (15). Apyrase used in the isolation of washed platelets was purified (16) and the quantity used was sufficient to block platelet aggregation by adenosine-5'-diphosphate, ADP $(20 \mu \mathrm{M})$, using a platelet aggregometer. Dog lung elastin, labeled with tritium using tritium gas at low pressure (17), was a generous gift of Dr. William Abrams of Graduate Hospital, Philadelphia, PA, and ${ }^{3} \mathrm{H}$-human lung elastin (18), labeled with ${ }^{3} \mathrm{H}$-labeled sodium borohydride (19), was kindly provided by $\mathrm{Dr}$. Phillip Stone, Department of Biochemistry, Boston University School of Medicine, Boston, MA. The radioactively labeled elastins were utilized after pretreatment with chymotrypsin (20) for determination of elastolytic activity. Diisopropyl fluorophosphate (DFP) was obtained from Aldrich Chemical Co., Milwaukee, WI, and was dissolved in anhydrous isopropyl alcohol (0.1 M) prior to use. Phenylmethylsulfonyl fluoride (PMSF) was obtained from Sigma Chemical Co.

Preparation of $\alpha_{2}$-macroglobulin free of $\alpha_{1}$-antitrypsin. These steps took advantage of the different precipitabilities of the two protease inhibitors, as well as their molecular size $(13,21-23)$. The $50 \%$ ammonium sulfate precipitate from $2 \mathrm{ml}$ of fresh-frozen, heparinized normal human plasma was passed through a Sephadex G-200 column $(2.5 \times 48 \mathrm{~cm})$ in $0.05 \mathrm{M}$ Tris $\mathrm{HCl}-0.1 \mathrm{M} \mathrm{NaCl}(\mathrm{pH} 7.5)$. The peak emerging at the void volume was pooled and concentrated to a volume of $\sim 4 \mathrm{ml}$ using an Amicon PM-10 membrane (Amicon Corp., Danvers, MA). The con. centrate was used as a source of native $\alpha_{2}$-macroglobulin.

$\alpha_{1}$-Antitrypsin has a $K_{\mathrm{av}}$ of $\sim 0.5$ on Sephadex G-200, allowing for removal of any trace amounts of this inhibitor from $\alpha_{2}$-macroglobulin. The native $\alpha_{2}$-macroglobulin preparation did not inhibit the trypsin hydrolysis of small substrates (24), e.g., BAPNA, confirming the removal of $\alpha_{1}$-antitrypsin. The preparation exhibited an immunoprecipitation band against antiserum to $\alpha_{2}$-macroglobulin but not against antiserum to $\alpha_{1}$-antitrypsin.

Assay and inactivation of $\alpha_{2}$-macroglobulin activity. The concentration of active $\alpha_{2}$-macroglobulin was determined as described by Schidlow and Kueppers (24). In this assay, an excess of active-site titrated trypsin is added to consume all trypsin inhibitors in the test sample, including $\alpha_{2}$-macroglobulin. When SBTI is then added to inhibit excess, free trypsin, the observable activity in the presence of BAPNA is due to trypsin bound to $\alpha_{2}$-macroglobulin. This is because trypsin which is bound to $\alpha_{2}$-macroglobulin is not subject to inhibition by SBTI and is fully active against low molecular weight substrates (24). The concentration of the $\alpha_{2}$-macroglobulin preparation used in these experiments was $0.132 \mathrm{mg} / \mathrm{ml}$.

The nucleophilic amine, methylamine, specifically inactivates the ability of $\alpha_{2}$-macroglobulin to inhibit proteinases (25). In order to verify the supposition that the inhibiting activity was due only to $\alpha_{2}$-macroglobulin, a sample $(1 \mathrm{ml})$ of the concentrate was treated as follows: the $\mathrm{pH}$ was adjusted to $8.0,26 \mu \mathrm{l}$ of $1 \mathrm{M}$ methylamine $\mathrm{HCl}$ was added, and the solution was incubated at $4^{\circ} \mathrm{C}$ overnight. For comparative purposes, a sample of $\alpha_{2}$-macroglobulin was carried through the same steps, omitting methylamine $\mathrm{HCl}$.

Immunosorbent column with IgG specific for human neutrophil elastase. The IgG fraction from goat antiserum to human neutrophil elastase was isolated by ammonium sulfate precipitation and chromatography on DEAE-cellulose by previously described methods (26). The purified $\operatorname{IgG}$ was then bound to cyanogen bromide-activated Sepharose 4B (27, 28 ), and the resulting immune immunosorbent material was equilibrated with $0.025 \mathrm{M}$ sodium phosphate- $0.5 \mathrm{M} \mathrm{NaCl}-0.05 \%$ Triton X-100 (pH 6.0 ). $\sim 0.33 \mathrm{mg}$ of IgG was bound per milliliter settled bed volume. A sample of normal goat serum was used to derive a nonimmune Sepharose 4B-IgG bound column material in order to verify that any antigen bound to the immunosorbent column was due to binding to specific IgG. The respective immune and nonimmune column materials were used to prepare $0.7 \times 8-\mathrm{cm}$ columns, using glass columns previously coated with Pro-Sil (PCR, Inc., Hialeah, FL) to retard nonspecific adsorption of neutrophil elastase. The columns were operated at $4^{\circ} \mathrm{C}$ at a flow rate of $4 \mathrm{ml} / \mathrm{h}$.

Preparation of platelets by a washing procedure. Platelets were isolated using the method of Mustard et al. (29), with minor modifications designed to remove leukocytes more effectively. Blood from volunteer donors (one donor unit $\sim 500 \mathrm{ml}$ ) was anticoagulated with acid citratedextrose in 50-ml aliquots and centrifuged at $225 \mathrm{~g}$ using swinging buckets in a Sorvall RC-3 centrifuge (DuPont-Sorvall, Newtown, CT) at room temperature for $20 \mathrm{~min}$. The upper two-thirds of the resulting supernatant, platelet-rich plasma (PRP), was very carefully withdrawn using a plastic syringe with attached Tygon tubing and was centrifuged again in the same manner.

After the second centrifugation, the upper three-fourths of the contents of the tubes was carefully withdrawn and the platelets were recovered by centrifugation at $990 \mathrm{~g}$ at room temperature for $20 \mathrm{~min}$. The pelleted platelets were then resuspended in four $40-\mathrm{ml}$ volumes of Tyrode's buffer with albumin $(3.5 \mathrm{mg} / \mathrm{ml})$, dextrose $(0.1 \mathrm{~g} / 100 \mathrm{ml})$, heparin $(60 \mathrm{U} / \mathrm{ml})$, $\mathrm{PGE}_{1}(1 \mu \mathrm{M})$, and apyrase $(150 \mu \mathrm{l} / 40 \mathrm{ml})$. After incubation for $20 \mathrm{~min}$ at $37^{\circ} \mathrm{C}$ the suspensions were centrifuged in the same manner as in obtaining the platelet pellet. These steps were repeated twice without adding heparin. The platelets were then taken up in a total volume of 1 $\mathrm{ml}$ using the wash solution without heparin. This suspension was used to prepare a platelet lysate.

Platelet and total/differential leukocyte counting. Platelet concentration was measured in PRP and at selected steps in the platelet isolation procedure, by use of a model D2N Coulter Counter (Coulter Electronics, Inc., Hialeah, FL). Leukocyte concentrations were determined in the Coulter Counter. The percentages of each cell type were determined by standard techniques after using a Shandon Cytocentrifuge (Shandon Southern Instruments, Inc., Sewickley, PA) and staining of the resulting sedimented, isopropanol-fixed cells using Diff-Quik Solutions 1 and 2 (Harleco, Gibbstown, NJ).

Preparation of the platelet lysate. The purified platelet pellet resuspended in a total volume of $1 \mathrm{ml}$ was mixed with an equal volume of $0.05 \mathrm{M}$ sodium acetate containing $1 \%$ Triton $\mathrm{X}-100$ (pH 4.5). The resulting $\mathrm{pH}$ was $\sim 5.25$. Because the supernatant material obtained by high-speed centrifugation in a Beckman Microfuge (Beckman Instruments, Inc., Palo Alto, CA) exhibited the same activity for compound I as did the lysate before centrifugation, no additional steps were needed to insure complete extraction of the elastase-like activity. After allowing the samples to stand for $30 \mathrm{~min}$ at $4^{\circ} \mathrm{C}, 0.1-\mathrm{ml}$ aliquots were stored at $-70^{\circ} \mathrm{C}$. Each aliquot was thawed only once and held at $4^{\circ} \mathrm{C}$ during use.

Assay of elastase-like and trypsin activities using synthetic substrates. The tetrapeptides, compound I and compound II, were dissolved at a concentration of $0.2 \mathrm{mM}$ in a 9:1 (vol/vol) mixture of $0.05 \mathrm{M}$ Tris $\mathrm{HCl}$ (pH 7.5) and dimethyl sulfoxide. These solutions were then used in the assay of elastase activity described by Castillo et al. (30), employing a model J4-8960 spectrophotofluorometer (Aminco, Silver Spring, MD). A volume of $1 \mathrm{ml}$ of substrate was combined with test materials and buffer totaling $0.2 \mathrm{ml}$ in volume, and the hydrolysis of the substrates was monitored by measuring the change in relative intensity over time at $440 \mathrm{~nm}$ at $23^{\circ} \mathrm{C}$. Because the platelet lysate exhibited an increasing slope in activity up to $20 \mathrm{~min}$ by this assay, rates were taken as the slope at $20 \mathrm{~min}$ after initiation of the reaction mixtures.

The ability of the platelet lysate to hydrolyze the elastase substrate, SAPNA, was determined according to the method described by Bieth et al. (31). The change in absorbance at $410 \mathrm{~nm}$ was measured at $23^{\circ} \mathrm{C}$ for reaction mixtures composed of $1 \mathrm{ml}$ of substrate at $0.5 \mathrm{mg} / \mathrm{ml}$ in $0.2 \mathrm{M}$ Tris $\mathrm{HCl}(\mathrm{pH} \mathrm{8.0)}$ combined with a volume of test material and buffer and/or test reagents totaling $0.2 \mathrm{ml}$. Trypsin activity, based on a standard curve generated with 0.1-0.6 $\mu \mathrm{g}$ of active enzyme, was determined using BAEe spectrophotometrically by the method of Schwert and Takenaka (32).

Chymotrypsin-pretreated ${ }^{3} \mathrm{H}-$ dog and human lung elastins. The ${ }^{3} \mathrm{H}-$ dog lung elastin $(5 \mathrm{mg}$ ) was mixed with $250 \mathrm{mg}$ of unlabeled dog lung elastin and washed four times by suspension in distilled water and centrifugation, followed by washing in a similar manner with 200 -ml volumes of the assay buffer containing $0.05 \mathrm{M}$ Tris $\mathrm{HCl}-0.14 \mathrm{M} \mathrm{NaCl}-0.2 \%$ Triton $\mathrm{X}-100$ (pH 8.0). Washing was continued until $<20 \mathrm{cpm} / \mathrm{ml}$ of wash supernatant was measured after centrifugation. The washed elastin was suspended in the same buffer at $1 \mathrm{mg} / \mathrm{ml}$ and was then pretreated (20) with $\alpha$-chymotrypsin (Worthington Biochemical Corp., Freehold, NJ), code CDI 2 LX. The final product had a specific radioactivity of 1.8 $\times 10^{5} \mathrm{cpm} / \mathrm{mg}$ elastin. Under the assay conditions described below, neither trypsin nor chymotrypsin were capable of releasing radioactivity from the chymotrypsin-pretreated ${ }^{3} \mathrm{H}$-elastin. 
The ${ }^{3} \mathrm{H}$-human lung elastin was suspended at a concentration of 1 $\mathrm{mg} / \mathrm{ml}$ and treated in the same manner as dog elastin, except that the initial washing steps were omitted. The human elastin had a specific radioactivity of $5.7 \times 10^{5} \mathrm{cpm} / \mathrm{mg}$ elastin. Neither trypsin nor chymotrypsin was capable of releasing radioactivity from the preparation above the level observed for incubation with buffer alone.

Measurement of elastolytic activity using chymotrypsin-pretreated ${ }^{3} \mathrm{H}$ dog and human lung elastins. For assays using ${ }^{3} \mathrm{H}$-dog lung elastin, 3$\mathrm{ml}$ volumes of the material at a concentration of $1 \mathrm{mg}$ elastin $/ \mathrm{ml}$ in 0.05 $\mathrm{M}$ Tris $\mathrm{HCl}-0.14 \mathrm{M} \mathrm{NaCl}-0.2 \%$ Triton X-100 (pH 8.0) were added to siliconized Reacti-Vials (Pierce Chemical Co., Rockford, IL) with Teflon stirrers. The total volume of test sample and/or buffer or test reagents added to the elastin was $0.3 \mathrm{ml}$. Preliminary tests revealed that incubation at $37^{\circ} \mathrm{C}$ resulted in rapid loss of activity of the platelet lysate.

The reaction mixtures were incubated at room temperature $\left(23^{\circ} \mathrm{C}\right)$ with constant stirring, and $0.3-\mathrm{ml}$ aliquots were removed at selected times for assay of radioactivity in the supernatant following centrifugation in a Beckman Microfuge. A blank containing appropriate amounts of the buffer components of the platelet lysate and the assay buffer was included to subtract observed spontaneous release of radioactivity from the ${ }^{3} \mathrm{H}$-elastin during the course of the assay.

$\alpha_{1}$-Antitrypsin and elastatinal were diluted in assay buffer before their inhibitory capacities were tested. $\alpha_{1}$-Antitrypsin $(0.5 \mathrm{mg})$ was added to the platelet lysate in a total volume of $0.3 \mathrm{ml}$ and the mixture was preincubated for $10 \mathrm{~min}$. Elastatinal $(3 \mathrm{mg}$ ) was similarly preincubated with the lysate and the mixture was assayed. All values presented in the text were derived by subtracting the blank values from those of the test samples. Aliquots were diluted in BioFluor scintillation liquid (New England Nuclear, Boston, MA) and assayed in a Searle Isocap 300 liquid scintillation counter (Nuclear-Chicago Corp., Des Plaines, IL) until constant counts were observed.

Assays employing chymotrypsin-pretreated ${ }^{3} \mathrm{H}$-human lung elastin were carried out in the same way as dog lung elastin assays. Combinations of sample volumes and the suspended radioactively labeled elastin were used as elaborated in Results.

Affinity separation on dog lung elastin. It was considered desirable for the sake of experimental continuity to use the same material for affinity separation as used in the assay of platelet lysate activity. Therefore, a sample $(10 \mathrm{mg})$ of the chymotrypsin-pretreated ${ }^{3} \mathrm{H}-\mathrm{dog}$ lung elastin was used in an experiment to separate elastolytic activity from the platelet lysate using the methodology of Legrand et al. (4).

Determination of the $\mathrm{pH}$ dependence of platelet elastase-like activity. The effect of $\mathrm{pH}$ on the hydrolysis of compound I was determined using the material derived by affinity separation of activity from the rest of the platelet lysate on the elastin. The buffer employed was $0.04 \mathrm{M}$ Tris $\mathrm{HCl}$ (pH 7.5). Different pH values were obtained by the addition of concentrated $\mathrm{HCl}$ or $\mathrm{NaOH}$.

Determination of the apparent mass ratio of platelet lysate enzyme. The platelet lysate prepared from washed platelets was dialyzed against $0.05 \mathrm{M}$ sodium acetate $(\mathrm{pH} 4.5)$ for a period of $2 \mathrm{~h}$ at $4^{\circ} \mathrm{C}$ with three changes. The dialyzed sample was centrifuged, and the clear supernatant material was injected onto an I-250 protein column for gel filtration by high-pressure liquid chromatography (Waters Associates, Inc., Milford, MA). The flow rate was maintained at $1 \mathrm{ml} / \mathrm{min}$, and $0.5-\mathrm{ml} \mathrm{frac-}$ tions were collected. The activity in the fractions for hydrolysis of compound I was measured immediately upon elution, using an equal volume $(0.5 \mathrm{ml})$ of the substrate at a concentration of $0.4 \mathrm{mM}$. Molecular weight standards (Blue Dextran 2000, albumin, chymotrypsinogen A, and ribonuclease A) were obtained from Pharmacia Fine Chemicals, Piscataway, NJ. The elution time for the platelet enzyme was determined by activity measurements on collected fractions. A plot of $\log$ of the apparent mass ratio of standards versus elution time was then used to estimate the apparent mass ratio for the platelet enzyme.

\section{Results}

Removal of leukocytes during platelet purification. A total of 8.3 $\times 10^{10}$ platelets, or $64 \%$ of the average number of platelets present $\left(\sim 1.3 \times 10^{11}\right)$ in a donor unit of blood (33), was present in the

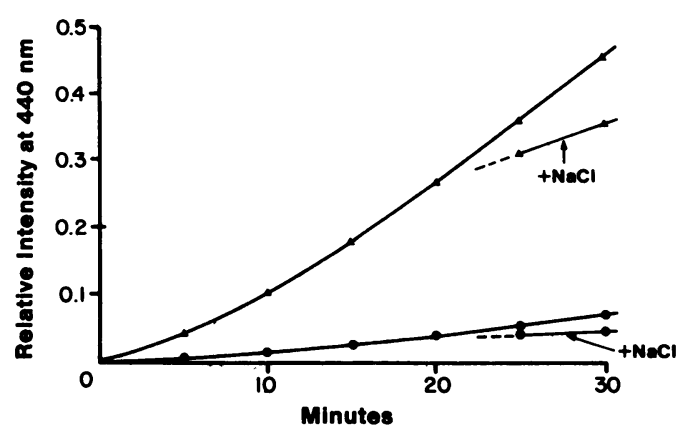

Figure 1. Amidolysis of fluorescence-labeled tetrapeptide elastase substrates by the platelet lysate. The rate of degradation of compound I $(\Delta)$ and compound II ( $\bullet$ ) by $20 \mu$ l of the lysate was measured in the presence and absence of $0.5 \mathrm{M} \mathrm{NaCl}$.

initially derived PRP (upper two-thirds). The latter contained $4.9 \times 10^{3}$ neutrophils, $87.5 \times 10^{3}$ lymphocytes, and $8.3 \times 10^{3}$ monocytes per $2.8 \times 10^{9}$ platelets. After the second centrifugation the PRP (upper three-fourths) contained a total of $4.9 \times 10^{10}$ platelets, no detectable neutrophils, 467 lymphocytes, and no detectable monocytes per $2.8 \times 10^{9}$ platelets. The final recovery of washed platelets was $\sim 22 \%$. The leukocyte content of $10 \%$ $\left(2.8 \times 10^{9}\right.$ platelets) of the total number of platelets obtained at the end of the washing procedure was measured. Only $18 \mathrm{lym}$ phocytes were observed.

Comparison of platelet lysate activity with that of purified neutrophil elastase using synthetic substrates. Elastase-like activity in the platelet lysate was measured with the fluorescencelabeled tetrapeptides. The results are shown in Fig. 1. There is a sevenfold higher rate of degradation of compound I than compound II by the lysate. The rates of hydrolysis for both substrates increased with time up to $\sim 20$ min. Addition of $\mathrm{NaCl}$ (final concentration, $0.5 \mathrm{M}$ ) at $20 \mathrm{~min}$ resulted in a $58 \%$ inhibition of the activity for both substrates.

The elastase-like activity of neutrophil elastase was tested under identical conditions. The results are shwon in Fig. 2. Neutrophil elastase hydrolyzed compounds I and II at a constant rate, but the rate of hydrolysis of compound II was seven times higher than that of compound I. In the presence of $0.5 \mathrm{M} \mathrm{NaCl}$, the rate of hydrolysis (measured as change in relative intensity) of compound II increased from 0.014 to $0.065 \mathrm{U} / \mathrm{min}$, and the rate of hydrolysis of compound I increased from 0.002 to 0.013 $\mathrm{U} / \mathrm{min}$.

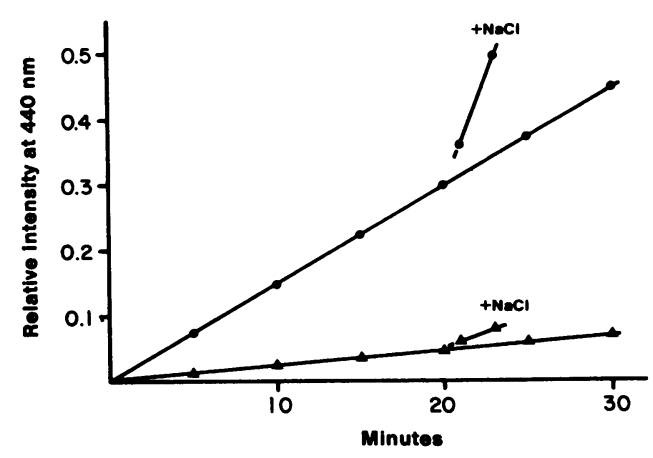

Figure 2. Amidolysis of fluorescence-labeled tetrapeptide elastase substrates by purified human neutrophil elastase. The rate of hydrolysis of compound I ( $\iota$ ) and compound II ( $\bullet$ ) by $0.25 \mu \mathrm{g}$ of enzyme was measured in the presence and absence of $0.5 \mathrm{M} \mathrm{NaCl}$. 
The platelet elastase-like activity was also compared with that of neutrophil elastase with the commonly used substrate, SAPNA. Although the rate of hydrolysis of SAPNA in the lysate was quite low (change in absorbance at $410 \mathrm{~nm}$ of $0.00036 \mathrm{U} /$ min for $20 \mu$ l of the lysate), it was found to increase with time, approximately doubling after 20 min of incubation. When $\mathrm{NaCl}$ was added to the reaction mixture at $20 \mathrm{~min}$, the activity of the platelet lysate was inhibited. In contrast, neutrophil elastase hydrolyzed SAPNA at a constant rate (change in absorbance at $410 \mathrm{~nm}$ of $0.0024 \mathrm{U} / \mathrm{min}$ for $1 \mu \mathrm{g}$ of the enzyme), and the activity was increased about twofold by $\mathrm{NaCl}$.

Effects of inhibitors on the elastase-like activity of the platelet lysate and neutrophil elastase. A number of organic and inorganic reagents were tested to determine whether they inhibit the elastase-like activity of the platelet lysate and neutrophil elastase. Compound I was used to evaluate inhibition of platelet lysate $(20 \mu \mathrm{l})$, and SAPNA was used for neutrophil elastase (1 $\mu \mathrm{g})$. The irreversible serine protease inhibitors, DFP $(20 \mathrm{mM})$ and PMSF $(25 \mathrm{mM})$, produced $33.5 \%$ and $75.0 \%$ inhibition, respectively, of the lysate activity. They produced $100 \%$ inhibition of neutrophil elastase activity. Furoyl-saccharin $(0.25 \mathrm{mg} / \mathrm{ml})$ inhibited lysate activity by $50.9 \%$ and neutrophil elastase by $100 \%$. Mercaptoethanol (1 mM) and EDTA ( $25 \mathrm{mM})$, not known to alter the activity of neutrophil elastase, likewise had no effect on platelet lysate activity. Addition of $\mathrm{HgCl}_{2}$ to the reaction mixture with the platelet lysate resulted in extreme turbidity and apparent complete inhibition. However, when the precipitated material was reconstituted in a new reaction mixture without $\mathrm{HgCl}_{2}$, $\sim 50 \%$ of the activity was regained. This indicates a nonspecific removal of the platelet lysate activity by metal ion precipitation, rather than involvement of a sulfhydryl moiety.

Purified $\alpha_{1}$-antitrypsin had no effect on the elastase-like activity of the platelet lysate (Table I). This unexpected finding illustrates the most outstanding difference between the platelet lysate and neutrophil elastase activities. Trasylol inhibited both the activity in the lysate and neutrophil elastase. Elastatinal was also an effective inhibitor of both the lysate activity and of neutrophil elastase. The remaining three bacterial inhibitors, chymostatin, antipain, and leupeptin, had no effect on the lysate activity or on neutrophil elastase.

Inhibition of neutrophil elastase and other proteases by the platelet lysate. Platelets are known to contain $\alpha_{1}$-antitrypsin and $\alpha_{2}$-macroglobulin $(34,35)$ and perhaps other protease inhibitors. In assay systems for protease inhibitors which use low molecular weight substrates (36), inhibition of enzymes by $\alpha_{2}$-macroglob-

Table I. Effect of Protein/Peptidyl Inhibitors

\begin{tabular}{lcc}
\hline & \multicolumn{2}{c}{ Percent inhibition of enzyme activity } \\
\cline { 2 - 3 } Inhibitor (Concn) & Platelet lysate & Neutrophil elastaseł \\
\hline & $\%$ & $\%$ \\
$\alpha_{1}$-antitrypsin $(0.1 \mathrm{mg} / \mathrm{ml})$ & 0 & 100 \\
Trasylol $(1 \mathrm{mg} / \mathrm{ml})$ & 71.3 & 95.6 \\
Elastatinal $(0.3 \mathrm{mg} / \mathrm{ml})$ & 28.6 & 39.3 \\
Chymostatin $(0.3 \mathrm{mg} / \mathrm{ml})$ & 0 & 0 \\
Antipain $(0.3 \mathrm{mg} / \mathrm{ml})$ & 0 & 0 \\
Leupeptin $(0.3 \mathrm{mg} / \mathrm{ml})$ & 0 & 0
\end{tabular}

* Substrate: compound I ( $20 \mu$ l of platelet lysate). $\ddagger$ Substrate: SAPNA ( $1 \mu \mathrm{g}$ of neutrophil elastase). ulin would not be measured, because enzymes bound to this inhibitor have essentially an unaltered capacity for reacting with their respective low molecular weight substrates. Any $\alpha_{2}$-macroglobulin in the platelet lysate test material, which may have bound any part of the exogenous proteases in this experiment, would not result in observed inhibition. Exogenous proteases inhibited by $\alpha_{1}$-antitrypsin (36) or similar inhibitors in the platelet lysate would, on the other hand, exhibit decreased capacity to degrade low molecular weight substrates. This experiment was limited to the detection of elastase-like and trypsin-like activity, in that these methods provide a facile way of assessing the inhibitory capacity of the platelet lysate for neutrophil elastase and other proteases and of thereby providing supporting data that shows neutrophil elastase to be different from the endogenous platelet enzyme. Thus, neutrophil elastase and porcine pancreatic trypsin and elastase were each preincubated with platelet lysate. Inhibition of the two elastases was measured with compound I, taking into account the endogenous activity of the platelet lysate for compound I (see footnote to Table II). Inhibition of trypsin was measured spectrophotometrically with BAEe as substrate. The results are expressed as the quantity of enzyme inhibited per $1 \times 10^{9}$ platelets represented by the lysate (Table II). The lysate inhibits much more neutrophil elastase activity than pancreatic elastase or trypsin activity.

Degradation of ${ }^{3} \mathrm{H}$-dog lung elastin by the platelet lysate. An enzyme referred to as an elastase should be capable of degrading native elastin. The capacity of the platelet lysate to degrade chymotrypsin-pretreated ${ }^{3} \mathrm{H}$-dog lung elastin was tested (Fig. 3). Elastolytic activity using this substrate was found to be linear over a 3-h period and for release of up to $4,000 \mathrm{cpm} / 150 \mu \mathrm{l}$ of supernatant tested in the assay. As evinced by Fig. 3, $\alpha_{1}$-antitrypsin did not inhibit platelet lysate elastolytic activity. However, the highly specific elastase inhibitor, elastatinal, was an effective inhibitor of elastolysis by the platelet lysate. The elastolytic activity of the platelet lysate $(100 \mu \mathrm{l})$ was equivalent to that of 0.63 $\mu \mathrm{g}$ of neutrophil elastase or $0.42 \mu \mathrm{g}$ of porcine pancreatic elastase.

Inhibition of the elastolytic activity of the platelet lysate by $\alpha_{2}$-macroglobulin. The ability of $\alpha_{2}$-macroglobulin to inhibit elastolysis by platelet lysate and neutrophil elastase was measured using ${ }^{3} \mathrm{H}$-labeled human lung elastin. Appropriate amounts of

Table II. Inhibition of Proteases by Platelet Lysate

\begin{tabular}{ll}
\hline Protease & $\begin{array}{l}\text { Calculated micrograms } \\
\text { of enzyme inhibited per } \\
1 \times 10^{9} \text { platelets* }\end{array}$ \\
\hline Porcine pancreatic trypsin & 1.21 \\
Porcine pancreatic elastase & 0.54 \\
Human neutrophil elastase & 4.50
\end{tabular}

\footnotetext{
* The values are obtained by testing residual activity for the substrates as follows: compound I (human neutrophil elastase and porcine pancreatic elastase) and BAEe (porcine pancreatic trypsin). Platelet lysate, $20 \mu \mathrm{l}$ (representing $5.6 \times 10^{8}$ platelets), was mixed with $0.6 \mu \mathrm{g}$ of porcine pancreatic trypsin, $0.3 \mu \mathrm{g}$ of porcine pancreatic elastase, or $1.5 \mu \mathrm{g}$ of human neutrophil elastase. For the two elastases, the activity of the platelet lysate alone was subtracted from the observed rates of degradation of compound I to obtain a net rate due to residual activity of the added enzymes. The observed rates for platelet lysate, porcine pancreatic elastase alone, and human neutrophil elastase alone were $0.0195,0.8440$, and $0.0900 \Delta$ relative intensity at $440 \mathrm{~nm} / \mathrm{min}$, respectively.
} 


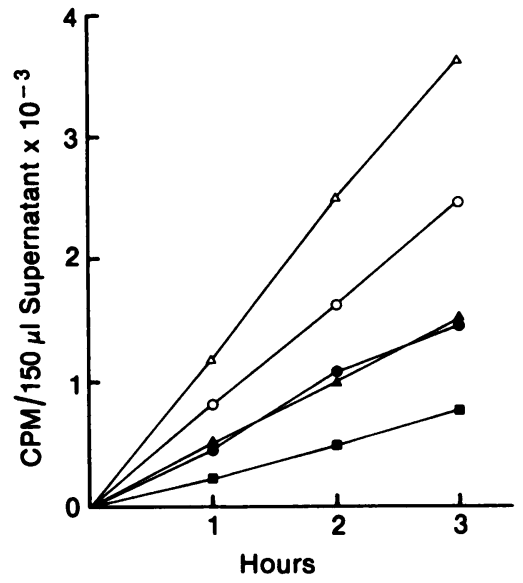

Figure 3. Effect of $\alpha_{1}$-antitrypsin and elastatinal on the digestion of ${ }^{3} \mathrm{H}$-dog lung elastin by the platelet lysate. The assay was carried out as described in Methods, using $100 \mu \mathrm{l}$ of platelet lysate per reaction mixture. Additionally, 1- $\mu \mathrm{g}$ amounts of porcine pancreatic elastase or human neutrophil elastase were tested for comparison with the lysate activity. The values shown are those minus the blank sample (see Methods). The symbols correspond to platelet lysate (৯); platelet lysate +

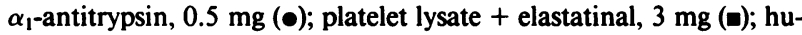
man porcine pancreatic elastase $(\Delta)$; and human neutrophil elastase (o).

the neutrophil enzyme $(0.3 \mu \mathrm{g})$ and lysate $(50 \mu \mathrm{l})$ were chosen so that their capacities to degrade compound I were identical. $\alpha_{2}$-Macroglobulin (5.28 $\mu \mathrm{g}$ of native or methylamine-inactivated material) was mixed with neutrophil elastase $(0.3 \mu \mathrm{g}$ in $50 \mu \mathrm{l}$ of the buffer components of the lysate) or platelet lysate $(50 \mu \mathrm{l})$, and the solutions were brought to $\mathrm{pH} 8.0$ and a total volume of $200 \mu$ l using $0.05 \mathrm{M}$ Tris $\mathrm{HCl}-0.1 \mathrm{M} \mathrm{NaCl}$. After incubation for $30 \mathrm{~min}$ at $4^{\circ} \mathrm{C}$, the samples were mixed with $400 \mu \mathrm{l}$ of ${ }^{3} \mathrm{H}$-human lung elastin at $1 \mathrm{mg} / \mathrm{ml}(\mathrm{pH} 9.0)$. Elastolysis was then measured as described in Methods. $\alpha_{2}$-Macroglobulin inhibited both enzymes by practically the same extent (Figs. $4 A$ and $B$ ). The neutrophil elastase and platelet lysate activities were inhibited by $66.0 \%$ and $68.4 \%$, respectively. Methylamine-inactivated $\alpha_{2^{-}}$ macroglobulin did not inhibit neutrophil elastase or the platelet lysate elastolytic activities.

Immunologic differentiation of platelet lysate elastase-like and elastolytic activities from neutrophil elastase. An immunosorbent column with purified goat IgG from immune serum against human neutrophil elastase and a control column with purified goat IgG from nonimmune serum were employed to further test whether the elastase-like and elastolytic activities of the platelet lysate could be related to neutrophil elastase. Amounts of neutrophil elastase and platelet lysate that had the same capacity to degrade compound I were utilized. Recovery of elastase-like activity from these columns is shown for neutrophil elastase in Fig. $5 A$ and for platelet lysate in Fig. $5 B$. The column buffer was chosen to minimize the adsorptive effect (observed in preliminary experiments) of the column supporting material toward neutrophil elastase without interfering with the antigen-antibody interaction. Data shown in Fig. $5 A$ reveal that neutrophil elastase could be specifically removed by the immune IgG column. $\sim 93 \%$ of the activity applied was recovered from the nonimmune IgG column and $17 \%$ from the immune IgG column. Data in Fig. $5 B$ show that platelet elastase-like activity did not bind to either column. Calculated recoveries of activity were $102.8 \%$ from the nonimmune and $104.3 \%$ from the immune IgG column.

Preliminary attempts to test aliquots of the platelet lysate fractions from these columns (as in Fig. $5 \mathrm{~B}$ ) for elastolytic activity using ${ }^{3} \mathrm{H}$-human lung elastin were unsuccessful because low levels of activity had been added to the column. To resolve this problem, an identical set of columns (Fig. 5 B) were run, and fractions 7-12 (corresponding to the bulk of the eluted elastase-like activity) were recovered and concentrated by Amicon PM-10 membrane to a volume of $2.5 \mathrm{ml}$. To this concentrated fraction, $2 \mathrm{ml}$ of ${ }^{3} \mathrm{H}$-human lung elastin $(1.5 \mathrm{mg} / \mathrm{ml}$ water $)$ was added. The $\mathrm{pH}$ was then adjusted to 8.0 and the samples were incubated at room temperature. Controls included a sample of platelet lysate equivalent to that applied to the column and a blank prepared with appropriate buffer components. Both were mixed with ${ }^{3} \mathrm{H}$-elastin and carried through the same steps. At 4 and $20 \mathrm{~h}, 700-\mu \mathrm{l}$ aliquots of the mixtures were centrifuged in a Beckman Microfuge and radioactivity was measured in $500-\mu \mathrm{l}$ aliquots of the supernatants tested for ${ }^{3} \mathrm{H}$ associated with soluble elastin peptides. After subtracting the blank value, the sample from the nonimmune column exhibited $4,112 \mathrm{cpm} / 500 \mu \mathrm{l} \cdot 16$ $h$ and the sample from the immune column exhibited 4,125 $\mathrm{cpm} / 500 \mu \mathrm{l} \cdot 16 \mathrm{~h}$. The untreated platelet lysate sample exhibited $4,580 \mathrm{cpm} / 500 \mu \mathrm{l} \cdot 16 \mathrm{~h}$. These results show that the IgG against neutrophil elastase did not remove the platelet elastolytic activity.

Affinity separation of platelet elastase-like activity using dog lung elastin. A 10-mg sample of ${ }^{3} \mathrm{H}$-dog lung elastin in $5 \mathrm{ml}$ of $0.05 \mathrm{M}$ Tris $\mathrm{HCl}-0.14 \mathrm{M} \mathrm{NaCl}-0.2 \%$ Triton X-100 (pH 8.0) was mixed with $0.5 \mathrm{ml}$ of the platelet lysate. The volume was brought to $15 \mathrm{ml}$ with the same buffer. After stirring for 30 minutes at room temperature, the mixture was centrifuged to recover the elastin, which was then washed two times by suspension and

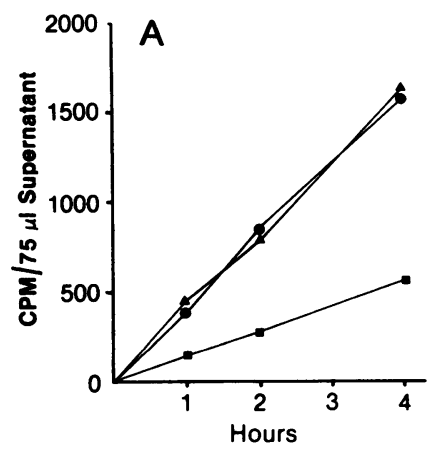

2334

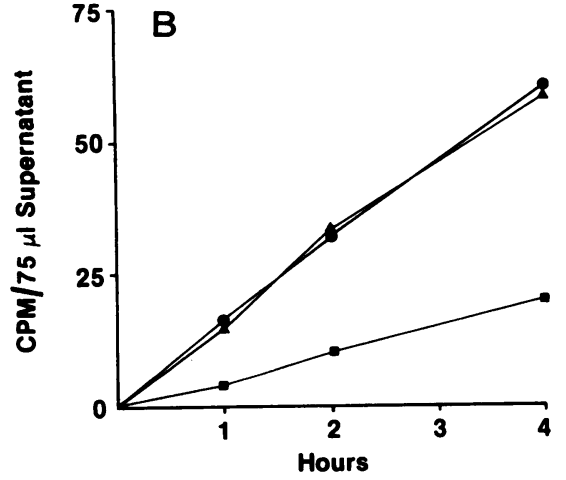

Figure 4. Inhibition of the elastolysis of ${ }^{3} \mathrm{H}$-human lung elastin by neutrophil elastase and the platelet lysate by $\alpha_{2}$-macroglobulin. ( $A$ ) The values represent neutrophil elastase, $0.3 \mu \mathrm{g}(\bullet)$; neutrophil elastase, $0.3 \mu \mathrm{g}$, preincubated $30 \mathrm{~min}$ with methylaminetreated $\alpha_{2}$-macroglobulin, $5.28 \mu \mathrm{g}(\Delta)$; and neutrophil elastase, $0.3 \mu \mathrm{g}$, preincubated $30 \mathrm{~min}$ with native $\alpha_{2}$-macroglobulin, $5.28 \mu \mathrm{g}(\boldsymbol{B})$. (B) The values represent platelet lysate, $50 \mu \mathrm{l}(\bullet)$; platelet lysate, 50 $\mu \mathrm{l}$, preincubated $30 \mathrm{~min}$ with methylamine-treated $\alpha_{2}$-macroglobulin, $5.28 \mu \mathrm{g}(\Delta)$; and platelet lysate, 50 $\mu$ l, preincubated $30 \mathrm{~min}$ with native $\alpha_{2}$-macroglobulin, $5.28 \mu \mathrm{g}(\boldsymbol{\theta})$. See the text for details. 


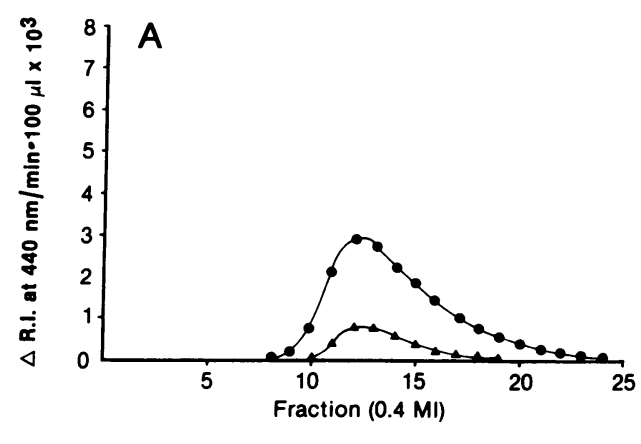

centrifugation in the same buffer. The resulting washed elastin pellet was suspended in $15 \mathrm{ml}$ of $1 \mathrm{M}$ sodium acetate- $0.01 \%$ Triton $\mathrm{X}-100\left(\mathrm{pH} \mathrm{4.5)}\right.$ and stirred for $5 \mathrm{~min}$ at $5^{\circ} \mathrm{C}$. The mixture was centrifuged at $2,000 \mathrm{~g}$ for $10 \mathrm{~min}$ at $5^{\circ} \mathrm{C}$, and the supernatant was recovered and concentrated to a volume of $0.5 \mathrm{ml}$ using an Amicon UM05 membrane. This concentrated eluate from elastin was dialyzed in $0.05 \mathrm{M}$ sodium acetate at $\mathrm{pH} 4.5$ and used for determination of elastolytic activity.

When the elastin eluate was tested for rate of degradation of compound I and compound II, the ratio of activity for I vs. II was 6.19 , a value close to that obtained by the same analysis of the platelet lysate (i.e., 5.47). Additionally, the elastin eluate activity was strongly inhibited by $\mathrm{NaCl}$ and was not affected by $\alpha_{1}$-antitrypsin.

Dependence of platelet elastase-like activity on $\mathrm{pH}$. The elastin eluate was used to determine the $\mathrm{pH}$ profile of elastase-like activity using compound I as substrate (Fig. 6). The pH optimum was between 8.5 and 9.0 .

Determination of the apparent mass ratio of the platelet enzyme by high-pressure liquid chromatography. A sample of platelet lysate was dialyzed rapidly over a period of $2 \mathrm{~h}$ at $5^{\circ} \mathrm{C}$ in three changes of $0.05 \mathrm{M}$ sodium acetate ( $\mathrm{pH} \mathrm{4.5).} \mathrm{The} \mathrm{dialysate}$ was centrifuged at $2,000 \mathrm{~g}$ for $10 \mathrm{~min}$ at $5^{\circ} \mathrm{C}$ to remove the platelet constituents which precipitated during dialysis. The resulting clear supernatant, $200 \mu$, was applied to a Waters I-250 protein column for high-pressure liquid chromatography and eluted at a flow rate of $1 \mathrm{ml} / \mathrm{min}$ (Fig. 7). Fractions of $0.5 \mathrm{ml}$ each were collected, and elastase-like activity was determined immediately, using an equal volume of compound I at twice the concentration usually employed in the fluorimetric assay. $\sim 75 \%$ of the activity applied to the column was recovered in the single activity peak obtained. The elution point of this activity peak

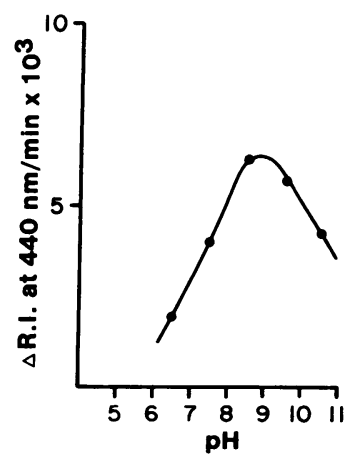

Figure 6. Effect of pH on elastin-separated platelet lysate elastase-like activity. The sample was added to compound $\mathrm{I}$ in $0.04 \mathrm{M}$ Tris $\mathrm{HCl}$, pH 7.5$10 \%$ dimethylsulfoxide (see Methods), and different $\mathrm{pH}$ values were obtained by addition of small quantities of concentrated $\mathrm{HCl}$ or $\mathrm{NaOH}$. R.I., relative intensity.
Figure 5. Recovery of elastase-like activity from neutrophil elastase immune IgG and nonimmune immunosorbent columns. The samples were eluted at $2^{\circ} \mathrm{C}$ with a buffer containing $0.025 \mathrm{M}$ sodium phosphate $-0.5 \mathrm{M}$ $\mathrm{NaCl}-0.05 \%$ Triton X-100 (pH 6.0). (A) Neutrophil elastase, $3 \mu \mathrm{g}$ in $250 \mu \mathrm{l}$ of buffer, was applied to both columns. Activity for compound I was determined for the immune $(\Delta)$ and nonimmune (๑) columns. (B) Platelet lysate, $250 \mu \mathrm{l}$ after dialysis in column buffer, was applied to both columns, and the activity for compound I was determined for the immune ( $\bullet$ ) and nonimmune ( $\bullet$ ) columns. R.I., relative intensity. corresponds to an apparent mass ratio of 23,000 daltons. This value is close to that previously determined $(26,000$ daltons) for a platelet elastolytic enzyme (4).

Attempts to release elastase-like activity by platelet stimuli. Preliminary studies were carried out to assess the possible release of elastase-like activity from platelets using low concentrations of effectors of the release reaction (37). When thrombin $(0.2 \mu$ / $\mathrm{ml})$, ADP $(5 \mu \mathrm{M}), \mathrm{ADP}$ in the presence of fibrinogen $(0.25 \mathrm{mg} /$ $\mathrm{ml})$, acid-soluble calf skin collagen $(0.19 \mathrm{mg} / \mathrm{ml})$, and epinephrine $(0.1 \mathrm{mM})$ were added to fresh washed platelets, little or no release of elastase-like or elastolytic activity could be detected. The platelets were, however, capable of undergoing normal aggregation (37) by these stimuli.

\section{Discussion}

Purified platelets were isolated essentially free of leukocytes. No neutrophils were observed when $10 \%\left(2.8 \times 10^{9}\right.$ platelets $)$ of those finally recovered from a unit of blood by the washing procedure were examined by differential cell counting. Lysis of 1 $\times 10^{6}$ neutrophils results in release of at least $1 \mu \mathrm{g}$ of active elastase (38). On the basis of the activity in the lysate for compound I, contamination of the washed platelets with $\sim 1.75$ $\times 10^{7}$ neutrophils $/ 2.8 \times 10^{9}$ platelets would be required to give the observed activity. Based on the activity in the lysate for compound II, $5.4 \times 10^{5}$ neutrophils $/ 2.8 \times 10^{9}$ platelets would be required to give the observed activity. Therefore, the observed activity for these substrates cannot be accounted for by neutrophil

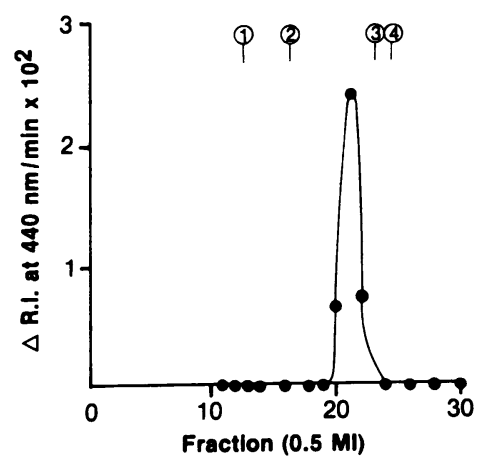

Figure 7. Analysis of Waters I-250 column fractions of the platelet lysate for elastase-like activity. Activity in selected fractions for compound I was determined immediately upon collection, as described in the text. The circled numbers at the top show the points of elution of apparent mass ratio standards: (1) Blue Dextran $\left(2 \times 10^{6} \mathrm{dal}-\right.$ tons), (2) human serum albumin (68,000 daltons), (3) ribonuclease $\mathrm{A}$ ( 13,700 daltons), (4) Trasylol (6,000 daltons). 
contamination. The failure of antibody specific for neutrophil elastase to adsorb the elastolytic activity from lysed platelets excludes the neutrophil as a source of elastase in platelets.

Those studies $(8,9)$ that indicated the apparent absence of an elastase in platelets might be explained principally on the basis of low levels of observable activity using some substrates. As indicated by our data using SAPNA as substrate and by the data obtained with ${ }^{3} \mathrm{H}$-human lung elastin (Fig. 3), the values were quite low and their validity had to be, in our experience, carefully evaluated. The availability of the fluorescence-labeled compounds I and II, as well as ${ }^{3} \mathrm{H}$-dog lung elastin, provided data more clearly interpretable, and provided the means of better assessment of the effects of inhibitors.

Platelet lysate activity increased with time when tested with compounds I and II and SAPNA assays. Although our results do not further address this observation, the effect could be caused either by an associated inhibitor which dissociates or becomes inactive during the assay procedure or by the activation of a proenzyme (4). Sodium chloride inhibits the platelet enzyme activity, whereas $\alpha_{1}$-antitrypsin has no effect. These agents have the opposite effect on neutrophil elastase. Inhibition of the platelet lysate elastase-like activity by DFP and PMSF, although partial in extent under the conditions utilized, indicates that the activity is due to a serine protease. The latter findings admit the possibility that more than one platelet elastase exists. Additionally, it is possible that a fraction of the observed activity for compound I could derive from an enzyme other than a serine protease type platelet elastase. The platelet enzyme of the present study therefore resembles those serine proteases which are poorly inhibited or not inhibited by $\alpha_{1}$-antitrypsin, such as clotting factor XII, plasma kallikrein, prekallikrein activator, and thrombin (39).

The fact that the platelet lysate inhibits $\sim 5-10$ times the quantity of neutrophil elastase as porcine trypsin or elastase (see Table II) indicates that one or more inhibitors against neutrophil elastase other than $\alpha_{1}$-antitrypsin may exist in platelets. This observation further substantiates that the elastase-like and elastolytic activities in platelets are not due to neutrophil elastase.

Although the platelet lysate elastolytic activity is not inhibited by $\alpha_{1}$-antitrypsin, it is inhibited by $\alpha_{2}$-macroglobulin. The amounts of neutrophil elastase and platelet lysate chosen were based on equivalent activities using compound I and were inhibited to virtually the same extent by $\alpha_{2}$-macroglobulin. Neutrophil elastase $(0.3 \mu \mathrm{g})$ was inhibited $66.0 \%$ and the platelet lysate activity was inhibited $68.4 \% . \alpha_{2}$-Macroglobulin binds to enzymes in a 1:1 molar ratio (40). If one molecule of $\alpha_{2}$-macroglobulin (725,000 daltons) binds one molecule of the platelet enzyme (23,000 daltons), then it is possible to estimate the quantity of the enzyme per $1 \times 10^{9}$ platelets. On this basis, 0.245 $\mu \mathrm{g}$ of the enzyme was present in $50 \mu \mathrm{l}$ of the lysate tested, and this concentration is equivalent to $0.175 \mu \mathrm{g}$ of the enzyme/1 $\times 10^{9}$ platelets. These calculations lead to the conclusion that neutrophils contain much more elastase on a molar basis than do platelets. The platelets in a $\mathrm{ml}$ of blood, $0.26 \times 10^{9}$ platelets (33), are thus estimated to contain $0.046 \mu \mathrm{g}$ of elastase, whereas the neutrophils in $1 \mathrm{ml}$ of blood contain $\sim 9 \mu \mathrm{g}$ of elastase (38). Determination of an apparent mass ratio of 23,000 daltons corresponding to the activity of the platelet enzyme proves that it is not bound to $\alpha_{2}$-macroglobulin in the lysate.

The attempts made to effect release of the elastase-like and elastolytic activities from platelets using effectors at low concentrations (37) indicated that the enzyme could be located in the cytosol. Studies are currently being conducted to further investigate this possibility.

In conclusion, platelets contain an enzyme with elastolytic activity. The activity is not due to the presence of neutrophil elastase and it is not inhibited by $\alpha_{1}$-antitrypsin. Inhibition of the enzyme by $\alpha_{2}$-macroglobulin might have significance in situations such as adult respiratory distress syndrome, where influx of platelet and plasma components occur in the lung under degradative circumstances.

\section{Acknowledgments}

The authors would like to express their appreciation to Mrs. Dagmar Skee, Ms. Marjorie Stevenson, and Mr. Joseph O'Brien for expert technical assistance. Additionally, helpful discussions and sharing of information with Mrs. Bonnie Ashe and Mr. Rick Mumford are gratefully acknowledged.

This work was supported by grants 5 P01 HL-20994 and R01 HL24365 of the National Heart, Lung and Blood Institute, National Institutes of Health, and by grant no. 1420 from the Council for Tobacco Research, USA.

\section{References}

1. Robert, B., Y. Legrand, G. Pignaud, J. Caen, and L. Robert. 1969. Activate elastinolytique associee aux plaquettes sanguines. Pathol. Biol. 17:615-622.

2. Robert, B., M. Szigeti, L. Robert, Y. Legrand, G. Pignaud, and J. Caen. 1970. Release of elastolytic activity from blood platelets. Nature (Lond.). 227:1248-1249.

3. Legrand, Y., B. Robert, M. Szigeti, G. Pignaud, J. Caen, and L. Robert. 1970. Études sur une protease elastinolytique des plaquettes sanguines humaines. Atherosclerosis. 12:451-465.

4. Legrand, Y., G. Pignaud, and J. P. Caen. 1977. Purification of platelet proteases: activation of proelastase by a trypsin-like enzyme. FEBS (Fed. Eur. Biochem. Soc.) Lett. 76:294-298.

5. Legrand, Y., J. P. Caen, L. Robert, and J. L. Wautier. 1977. Platelet elastase and leukocyte elastase are two different entities. Thromb. Haemostasis. 37:580-582.

6. Ohlsson, K., and L. Olsson. 1974. The neutral proteases of human granulocytes. Isolation and partial characterization of granulocyte elastases. Eur. J. Biochem. 42:519-527.

7. Baugh, R. J., and J. Travis. 1976. Human leukocyte granule elastase: rapid isolation and characterization. Biochemistry. 15:836-841.

8. Ehrlich, H. P., and J. L. Gordon. 1976. Proteinases in platelets. In Platelets in Biology and Pathology. J. L. Gordon, editor. Elsevier Science Publishing Co., Inc., New York. 353-372.

9. Starkey, P. M., J. L. Gordon, H. P. Ehrlich, and A. J. Barrett. 1978. Do platelets contain elastase? Thromb. Haemostasis. 39:542-543.

10. Zimmerman, M., B. Ashe, E. C. Yurewicz, and G. Patel. 1977. Sensitive assays for trypsin, elastase, and chymotrypsin using new fluorogenic substrates. Anal. Biochem. 78:47-51.

11. Zimmerman, M., H. Morman, D. Mulvey, H. Jones, R. Frankshun, and B. Ashe. 1980. Inhibition of elastase and other serine proteases by heterocyclic acylating agents. J. Biol. Chem. 255:9848-9851.

12. Umezawa, H. 1976. Structures and activities of protease inhibitors of microbial origin. Methods Enzymol. 45:678-695.

13. Cohen, A. B., and H. L. James. 1978. Evaluation of alpha-1antitrypsin as a potential therapeutic agent. In Proceedings of the International Workshop on Technology for Protein Separation and Improvement of Blood Plasma Fractionation, Publ. No. 78-1422. H. E. Sandberg, editor. U. S. Department of Health, Education and Welfare, National Institutes of Health, Bethesda. 326-338.

14. Shotton, D. M. 1970. Elastase. Methods Enzymol. 19:113-140.

15. Chase, T., Jr., and E. Shaw. 1970. Titration of trypsin, plasmin and thrombin with $p$-nitrophenyl p-guanidino-benzoate-HCl. Methods Enzymol. 19:20-27. 
16. Molnar, J., and L. Lorand. 1961. Studies on apyrase. Arch. Biochem. Biophys. 93:353-363.

17. Lively, M. O., G. A. Bush, B. P. Mathur, T. F. Moran, and J. C. Powers. 1980. Tritium labeling of thermolysin, elastase, and ribonuclease by exposure to tritium gas at low pressure. Arch. Biochem. Biophys. 204: 589-599.

18. Starcher, B. C., and M. J. Galione. 1976. Purification and comparison of elastins from different animal species. Anal. Biochem. 74: 441-447.

19. Stone, P. J., G. Crombie, and C. Franzblau. 1977. The use of tritiated elastin for the determination of subnanogram amounts of elastase. Anal. Biochem. 80:572-577.

20. Bielefield, D. R., R. M. Senior, and S. Y. Yu. 1975. A new method for determination of elastolytic activity using $\left[{ }^{14} \mathrm{C}\right]$ labeled elastin and its application to leukocytic elastase. Biochem. Biophys. Res. Commun. 67:1553-1559.

21. Schultze, H. E., and J. F. Heremans. 1966. Molecular Biology of Human Proteins with Special Reference to Plasma Proteins, Vol. 1. Elsevier, Amsterdam. 204.

22. Jones, J. M., J. M. Creeth, and R. A. Kekwick. 1972. Thiol reduction of human alpha-2-macroglobulin. The subunit structure. Biochem. J. 127:187-197.

23. Lo, T. N., A. B. Cohen, and H. L. James. 1976. The interaction of alpha-1-antitrypsin with soluble and Sepharose-bound elastase. Biochim. Biophys. Acta. 453:344-356.

24. Schidlow, D. V., and F. Kueppers. 1980. Trypsin binding activity of alpha-2-macroglobulin in cystic fibrosis and other lung diseases. Am. Rev. Respir. Dis. 121:31-37.

25. Swenson, R. P., and J. B. Howard. 1979. Structural characterization of human ${ }_{2} \mathrm{M}$ subunits. J. Biol. Chem. 254:4452-4456.

26. Fahey, J. L., and E. W. Terry. 1967. Ion exchange chromatography and gel filtration. In Handbook of Experimental Immunology. D. M. Weir, editor. F. A. Davis, Philadelphia. 19-43.

27. March, S. C., I. Parikh, and P. Cuatrecasas. 1974. A simplified method for cyanogen bromide activation of agarose for affinity chromatography. Anal. Biochem. 60:149-152.
28. Cuatrecasas, P., and C. B. Anfinsen. 1971. Affinity Chromatography. Methods Enzymol. 22:345-378.

29. Mustard, J. F., D. W. Perry, N. G. Ardlie, and M. A. Packham. 1972. Preparation of suspensions of washed platelets from humans. $\mathrm{Br}$. J. Haematol. 22:193-204.

30. Castillo, M. J., K. Nakajima, M. Zimmerman, and J. C. Powers. 1979. Sensitive substrates for human leukocyte and porcine pancreatic elastase: a study of the merits of various chromophoric and fluorogenic leaving groups in assays for serine proteases. Anal. Biochem. 99:53-64.

31. Bieth, J., B. Speiss, and C. G. Wermuth. 1974. The synthesis and analytical use of a highly sensitive and convenient substrate of elastase. Biochem. Med. 11:350-357.

32. Schwert, G. W., and Y. Takenaka. 1955. A spectrophotometric determination of trypsin and chymotrypsin. Biochim. Biophys. Acta. 16: 570-575.

33. Miale, J. B. 1977. Laboratory Medicine Hematology, 5th Edition. The CV Mosby Co., St. Louis. 992.

34. Bagdasarian, A., and R. W. Colman. 1978. Subcellular localization and purification of platelet alpha-1-antitrypsin. Blood. 51:139-156.

35. Nachman, R. L., and P. C. Harpel. 1976. Platelet alpha-2-macroglobulin and alpha-1-antitrypsin. J. Biol. Chem. 251:4514-4520.

36. James, H. L., and A. B. Cohen. 1978. Mechanism of inhibition of porcine elastase by human alpha-1-antitrypsin. J. Clin. Invest. 62: 1344-1353.

37. Holmsen, H. 1975. Biochemistry of the platelet release reaction. In Biochemistry and Pharmacology of Platelets. Ciba Found. Symp. 35: 175.

38. Janoff, A., I. P. Crawford, and M. Galdston. 1980. Leukocyte elastase-like activity in normal persons and in emphysematous patients with and without alpha-1-antitrypsin deficiency. Am. Rev. Respir. Dis. 121:1059-1060.

39. Movat, H. Z. 1979. The acute inflammatory reaction. In Inflammation, Immunity and Hypersensitivity, 2nd Edition. H. Z. Movat, editor. Harper and Row, New York. 59.

40. Barrett, A. J., and P. M. Starkey. 1973. The interaction of alpha2-macroglobulin with proteinases. Biochem. J. 133:709-724. 